\title{
Transition management applications to accelerate sustainable food consumption - comparative analysis between Switzerland and Hungary
}

\section{Csaba Fogarassy}

Climate Change Economics Research Centre Hungary,

Szent István University

Gödöllö, Hungary

fogarassy.csaba@gtk.szie.hu

\section{Huu Hoang Nguyen}

Climate Change Economics Research Centre Hungary, Szent István University

Gödöllö, Hungary

nhboangmta@gmail.com

\section{Judit Oláh}

Institute of Applied Informatics and Logistics,

Faculty of Economics and Business, University of Debrecen

Hungary

olah.judit@econ.unideb.hu (corresponding author)

\section{József Popp}

Institute of Sectoral Economics and Methodology, Faculty of Economics and Business, University of Debrecen

Hungary

popp.jozsef@econ.unideb.hu

Abstract. The aim of this paper is to present the transition towards sustainability and its characteristics in consumer systems of different levels. The relevance of the topic comes from the many development paths and innovation programmes which are initially recognized as sustainable in former socialist countries but which eventually all turn out to be unsuccessful. This study introduces the research which compares the sustainable consumer attitudes of the "50+" population in Switzerland and Hungary. The former is one of the most advanced consumer communities in Europe and the latter is a post-communist economy in transition. The representative sample, which contained over 1000 questionnaires and complementary personal interviews, clearly indicated the difference between the two groups of consumers. While among Swiss population marketing tools and social discussions to promote sustainable and (c) Foundation of International Studies, 2018 (c) CSR, 2018 Received:
March, 2018
1st Revision:
April, 2018
Accepted:
August, 2018

DOI:
10.14254/2071-
$8330.2018 / 11-3 / 3$ 
environmentally friendly consumption can easily be applied, in the case of Hungarian society we need to introduce new regulations and legislative standards to achieve the same aim. In the future, taking into account these results is highly recommended when considering the development of sustainability and political programmes.

Keywords: sustainable consumption, transition thinking, transition management, multi-level perspective, strategic transition, tactical transition, operative transition.

JEL Classification: O13, O17, O44, O52, D12, D78

\section{INTRODUCTION}

A 'transition thinking' perspective, as a reformed initiative of scientific thinking was designed as an academic concept during the early 1990's in the Netherlands. Its sphere of influence expanded slowly, but was more or less integrated on the establishment level by 2001, in the form of the Dutch Knowledge Network and Research Program for System Innovations and Transitions (KSI). The goal of KSI was mainly to make the process of sustainable innovation easier to understand, and to make people capable of identifying factors which have influence on this transformation process. In order to make the process of sustainable transition interpretable scientifically as well, ecology, complexity theory, sociology, history, leadership and management theory, and knowledge related to innovation processes were integrated into the analyses step by step (Sterrenberg et al., 2013).

Transition thinking and management fundamentally assist the description and development of realistic and inspirational goals and narratives. (Long-term) visions are paired with short-term operative projects in transition thinking, and implementing local and global processes and their connections into the equation becomes possible with this approach. Furthermore, it offers guidelines and advice on assembling either structural forms, or cooperation programs, which can prove efficient in reaching regional or national goals set in terms of sustainability (Wittmayer et al., 2016). These goals are mainly either clearly technological innovations, green innovations, or climate-friendly system development projects. Therefore, the engine of transition processes is made up of innovation programs, but in these cases, transition thinking also requires a new, system-level interpretation (Kemp et al., 2007).

Therefore, in order to get to know what attitudes the generally aging society of Europe really holds towards sustainability, and to be able to utilize their consumption habits to understand, for example, if innovation processes support or inhibit society's initiatives related to making sustainable systems - such as low-carbon way of life - we have conducted analyses of European consumers in two different development level groups. We chose the $50+$ generation group for our analyses, since it has the most notable influence on the development of sustainable consumption items with its consumption decisions, and on the formation of sustainable services. The goal of our research was to outline the general characteristics of transitioning to a sustainable consumption structure by this generation group, and to understand what kind of transition management strategy we can apply to the system processes we have identified (strategic, tactical, operative, reflexive); furthermore, to understand if we can determine if this transition management process can have different modes of implementation and fundamentally different solutions in Europe's different consumption systems. We also wish to acquire a clear view of which innovation system programs (i.e. green, low-carbon, clean-tech) can support these differences in the future. Based on the related OECD Study (OECD, 2008), when we are "designing effective sustainable consumption policies, general consumer 
behaviour (awareness, rationality) as well as attitudinal variables should be taken into account. For some consumers, income level and status concerns indicate that initiatives could build on their desire to make green statements or send social messages". In order to understand these processes, we structured the results of the questionnaire according to sustainability goal systems, with which we analysed two economies, in two different transition phases. One of them - Switzerland - is one of the most developed, which is at the forefront of the transition process, it was selected to show the socioeconomic innovation demands as they close in on the equilibrium point. The other analysis concerned the attitudes of Hungarian consumers, who are the citizens of the country which is currently at the initial phase of transition to preferring sustainability. We have made here an attempt to define the route towards which the related processes are developing in this case as a challenge, which can be followed by the acceleration phase later.

The first part of the paper shows the differences between linear and non-linear innovation models focusing in particular on how they support the sustainability principles. In the transition process different developmental phases can be distinguished, which also represent well-defined intervention strategies. Furthermore, we analyse theoretical inventions and practical experiences related to transition management details to show that the four different activities (strategic, tactical, operative, reflexive) can be defined within the contexts of actors' behaviour, and social transitions. Finally, the study presents the results demonstrating that the trends in sustainable and environmentally friendly consumption are influenced by very different factors if we compare Switzerland and Hungary.

\section{LITERATURE REVIEW}

In the literature review, we would like to present some of the most important contexts about the problems of linear innovation processes and the advantages of non-linear innovation practices. During the analysis of transition management, we present practical examples of transformation strategies and possible interventions.

\subsection{Linear and non-linear innovation models and processes}

Fundamental innovation theories have changed significantly over the last few years, but sadly, the innovation policies we currently use are mainly dependent on the traditionally accepted innovation theory the linear innovation model. In the linear model, the process of innovation generates the end result of a new product or process, which is basically a research result, or a product of the new technological solution. The basic linear-sequential mechanisms (Brooks, 1995) of the innovation process are maintained by the development of new technology.

\section{Research $\Rightarrow$ Development $\Rightarrow$ Production $\Rightarrow$ Diffusion}

Figure 1. The non-linear transition process

Source: based on Brooks (1995)

The linear model suggests that the most important actors in the innovation process are researchers and entrepreneur-developers. Later research validated the fact that this linear model is too simple. The most frequent actors in the process are the following: banks, shareholders, funding organizations, suppliers, NGOs, the government, and customers/end users.

Therefore, the non-linear innovation model has many actors, which makes it capable of not (only) generating a new technological solution, or product, but facilitating a complete transformation process. This 
non-linear transition process can be followed in Figure 1. Its basic laws are defined by the partners and their connections with each other. Therefore, innovation in and of itself is also a transition, which has an effect on the general behaviour of economic and social actors, and in case fortune smiles upon it, and it can establish a firm basis for long-term sustainable and continuously evolving structures (Horvath-Magda, 2017; Kot, 2018).

In the non-linear innovation model, financial systems actively partake in generating financial backing for the innovation or incubation process, while consumers use their consumption activities to assist market integration, and political or social actors take part in the transition management process via flexible efforts in regulation conditions.

The business sector sees the promotion of eco-efficiency as its role with respect to sustainable consumption. Most market players are established for the provision of mass consumption and the associated necessary inducement to ever increasing levels of consumption. There is only a limited "niche" for enterprises to distinguish themselves or their products on the basis of social and environmental conduct, regulations, and norms with corresponding price margins. Both, consumers and businesses, in turn, influence governments' positioning towards sustainable consumption (Loreka-Fuchsb, 2013).

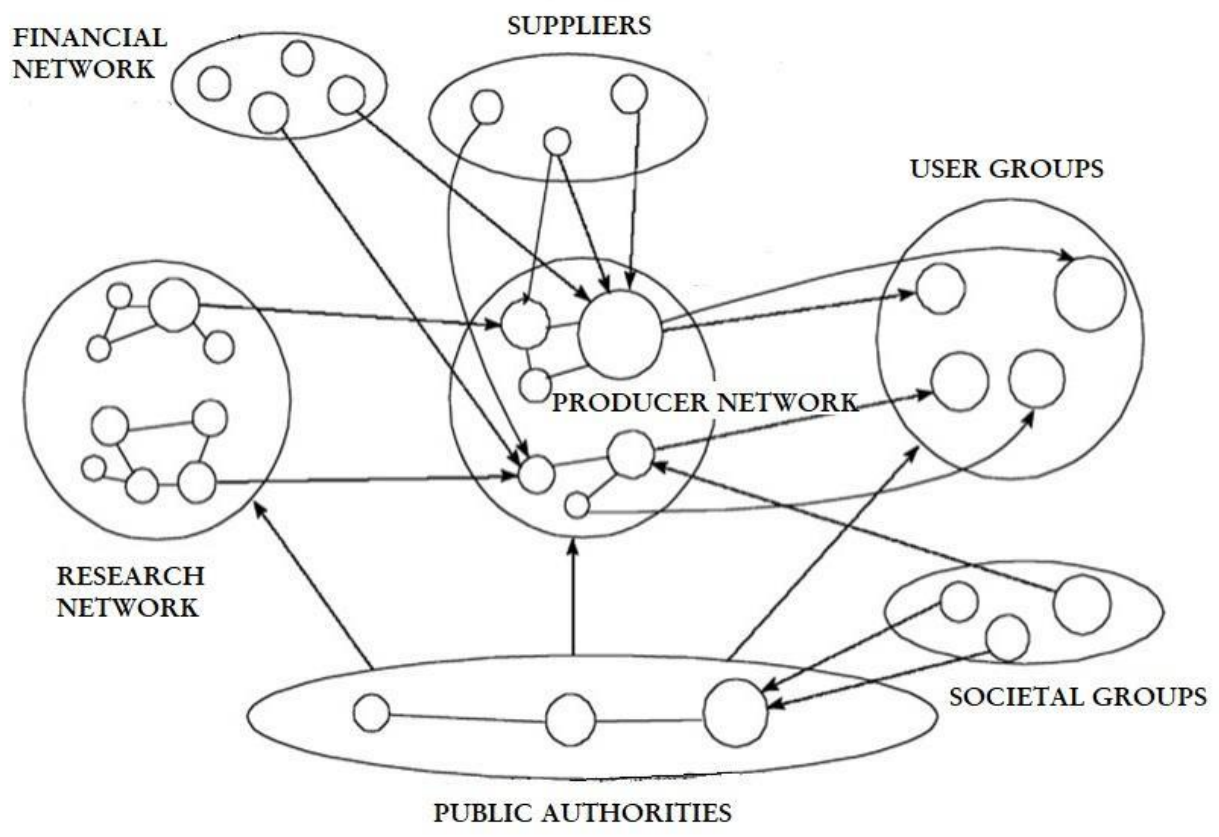

Figure 2. Actors in the transition process

Source: based on Sterrenberg et al. (2013)

\subsection{Interpretation of transition process and sustainable transition management}

'Transition thinking' and 'transition management' theories stem from a basic idea, retraceable to studies of complexity theory and ecosystem theory which consider sustainability as encompassing fundamental and system level changes, which are dependent on multiple actors, and whose connections are a decisive factor in the dynamics of transition processes (Ryan, 2013). The establishment of a low-carbon (low material- and energy-requirement) society - which is planned to be achieved in one or two generations - could create an equilibrium of various states in society, which can be observed in our own ecosystems as well. This description is combined in the process of transition management, with its multi-actor network ideas and 
multi-level process management (e.g. the Multi-Level Perspective) (Sterrenberg et al., 2013). Transition management basically differentiates between the states of a process: the initial phase, the acceleration phase, and the stabilization phase (the new equilibrium), which can be seen in Figure 3. We can apply the economicsocial systems we evaluate to the innovation curve of the system seen in Figure 3, which can draw an outline of the attributes and intervention points to be used for the transition. The fundamental questions of transition management are as follows: How can the attitude of society, currently not sustainable, become a sustainable one? When and how can this transition be measured? (Loorbach-Rotmans, 2009). It is hard to find the answer to the first question, because the group of innovation criteria include many elements which we are not able to handle with sufficient confidence. The non-generic lifestyle control in question depends on how conscious the participants and actors are of the consequences of their own actions, which have an effect on the development and innovation processes conducted on various levels of society. If the actions of actors are more in sync and well-structured, then we are on the road towards transition, where processes are easy to control, and can be accelerated well (Roorda et al., 2012).

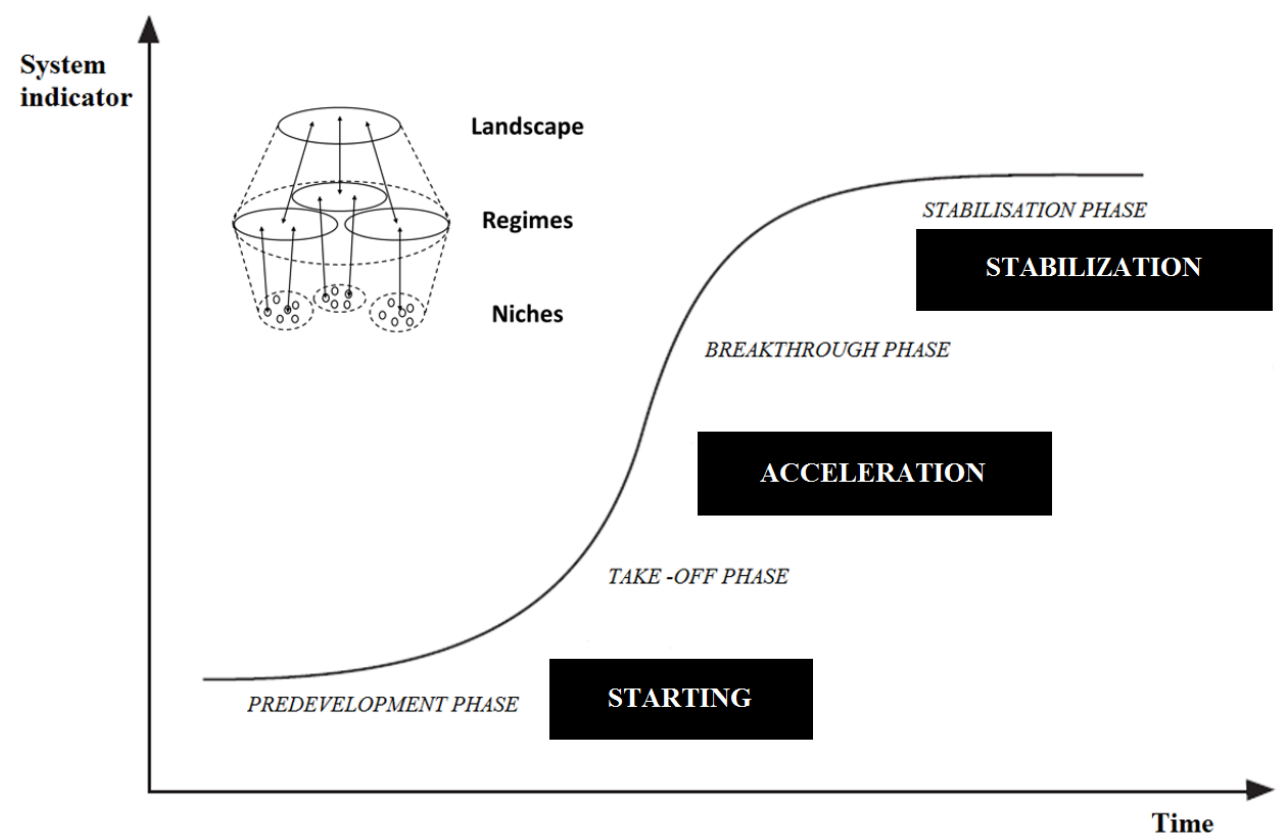

Figure 3. Phases of transition management

Source: based on Sterrenberg et al. (2013)

The theoretical inventions and practical experiences related to transition management gained during the last decade, show that the following four different activities can be defined within the contexts of actors' behaviour, and social transitions, (Loorbach, 2010): strategic, tactical, operative, reflexive.

Strategic transition: processes happening on a social level, which have a long-term actualization result, are related to structuring complex social problems, and constitute an alternative outlook on the future. The transformation and innovation of the pension system is closely related to the shape of the population pyramid. In developed countries, these are well-designed, long-term processes. In developing countries, changes in the population of the pension system have to be adopted by continuous changes. Basically, this means macro-level changes in society and the economy. 

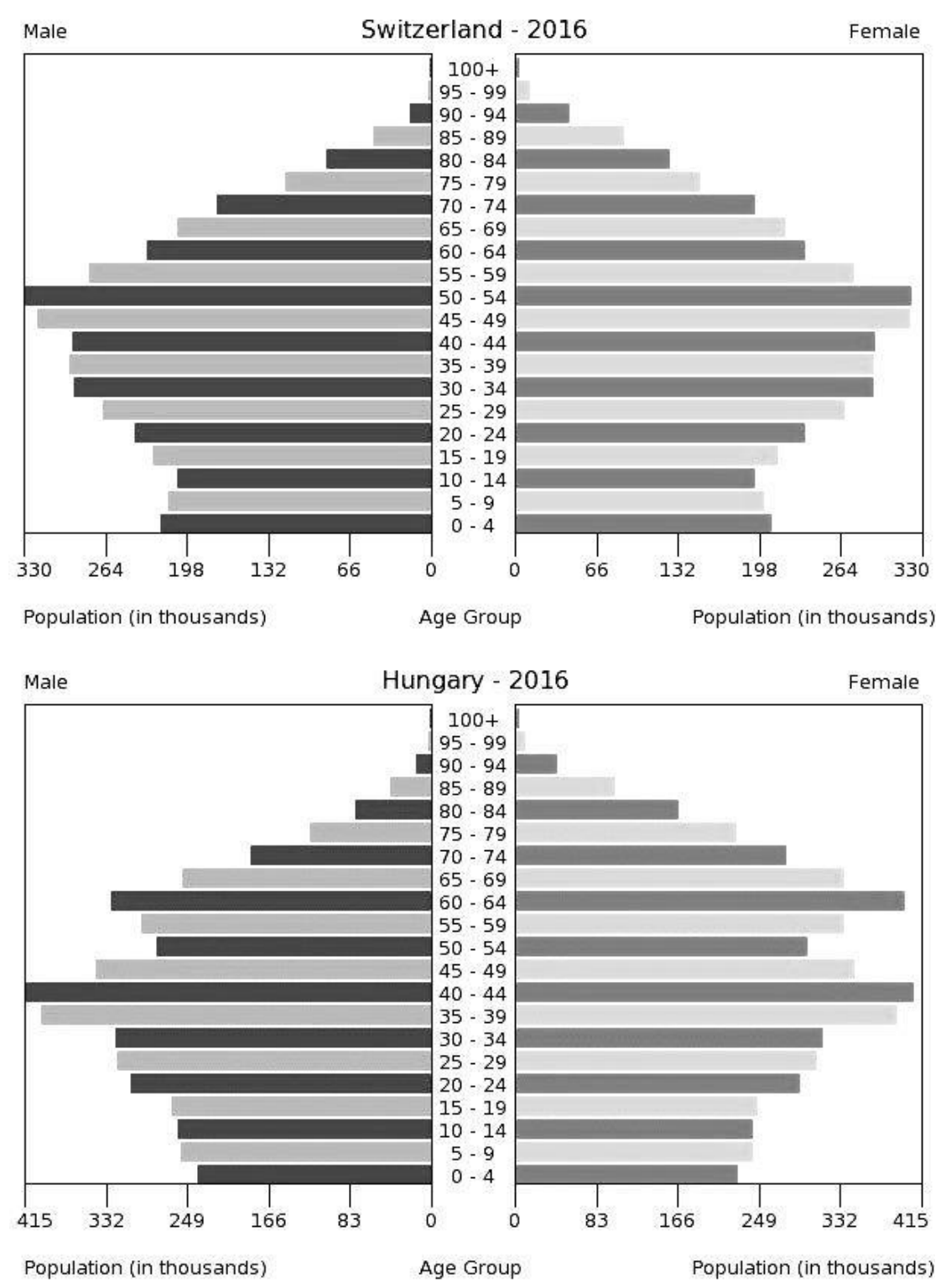

Figure 4. Population pyramids in Switzerland and Hungary, 2016 Source: World Factbook CIA (2018)

The Common Agricultural Policy (CAP) system can also be called a strategic or landscape planning level phenomenon because its regulatory elements provide a framework for agricultural production and innovation for a specified period of time in the EU (Lefebvre at al., 2014).

Tactical: activities that occur on the level of society, which bloom in the long-term, are related to the appearance of complex social problems, and generate an alternative future as a result of organic development. Without innovation programs, these activities cannot operate properly, which is why green or low-carbon strategic solutions make up the specifics of the innovations. A good example of this is when GHG emissions are priced so that the level of the system adds extra costs to the system users, so these are taken into account in their decisions. The same effect can be observed for foods as well, if we increase the price of products by regulation, their consumption decreases (Máté et al., 2017) By artificially reducing prices (e.g. with a Value Added Tax increase), their preference increases (HCSO, 2018). 
This is most notable in developed societies. Tactical activities are implemented on a sub-system level, and are related to the construction and deconstruction of the system's structure (institutions, regulations, physical infrastructure, monetary infrastructure, etc.). This is basically a subsystem change compared to the previous system. Figure 5 shows that the Swiss ETS (Emission Trading Scheme) covers the GHG emissions of the food sector, while the EU ETS system does not yet address this issue.

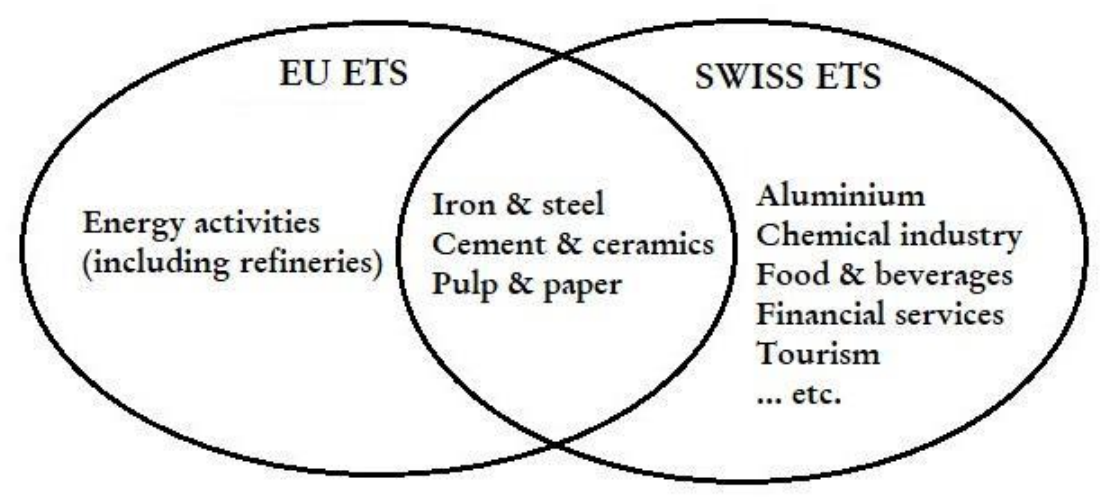

Figure 5. EU ETS and Swiss ETS sectoral activities

Source: Springer (2006)

Operative: activities related to short-term and everyday decisions and actions. On this level, the actors either rethink or reconstruct the structures of the system; furthermore, they decide if they should restructure, or only partially change them. The decision makers usually change regulation systems and generic base structures during the transition processes, and create new systems in the hope of reaching sustainability. These transformation processes are signified by, for example, state interventions in the form of privatization or de-privatization (e.g. reorganizing the ownership of land), or introducing new structures, or exchanging the old ones. The most notable fields subject to these are: waste management, wastewater treatment, health care, communal feeding, and agriculture. These programs usually appear in fast-developing countries, so we can see these processes happen in new Member States of the European Union. The effect of these influences is usually successful, but sometimes it may be wrong, which involves rescinding regulation.

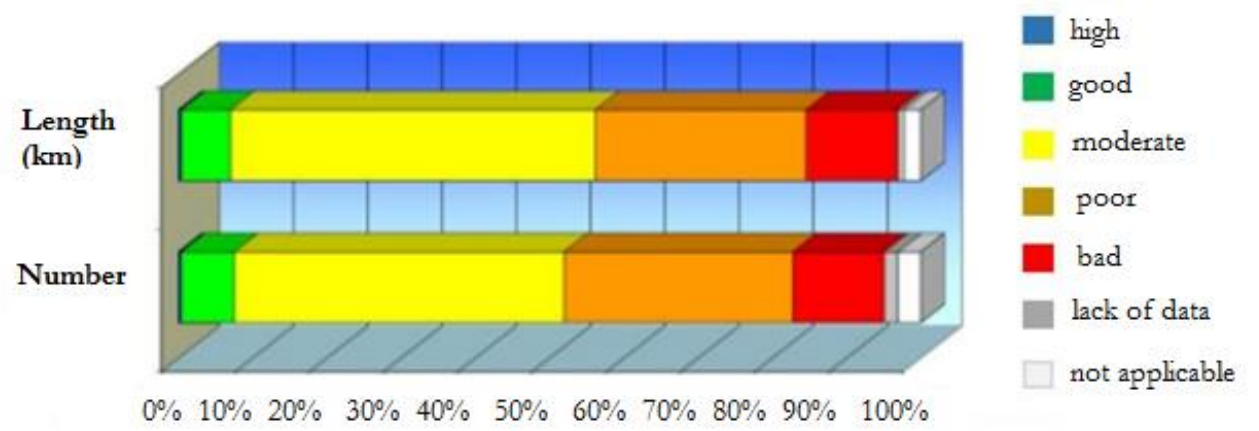

Figure 6. Ecological evaluation of rivers and streams based on their length and number Source: HAS (2017)

Figure 6 shows that $7 \%$ of flowing waters are in good ecological status/potential (no high status) and $88 \%$ are in worse than good status/potential. In developing countries (or transition countries), the pollution of the local environment often does not interfere with consumers, because rapid economic growth means 
the weight and importance of information cannot be perceived. Therefore, it is not taken into account in consumer decisions (water consumption, waste management norms) (Fogarassy-Neubauer, 2016). In developed countries, this phenomenon affects consumers together, as economic and social processes show a much slower tendency, so any negative or positive change can easily be perceived. Consumer responses therefore appear here directly.

Reflexive/retroactive: The multi-level evaluation of existing states and their detrimental by-products. Social events continuously structure themselves through the mediation of arguments, structured evaluation, analysis and research, while those affected rethink and treat problems. Learning from our own mistakes typically encompasses this transition. In this control process, we can often find phenomena where decision makers identify, or sense the consequences of, incorrect development processes, and thereby try to manage the processes of transition towards the correct route using changes in their current routes, or their goal system. Due to this sensing of disadvantageous feedback, all developments or innovations are the results of multi-level evaluation processes (Illés B. et al., 2015). Through discussions/arguments and analyses, social events continuously restructure themselves, and problems are rethought and handled using the effects sensed. Similar effects can be seen during the processes of alternative energy source developments, where the management of prioritized programs generates different effects in different EU Member States. In the case of different countries, mixed-up regulations, market preferences, or different lobby activities for the same goal system (f. e. EU 20-20-20) produce completely different social and economic reactions (Figure 7). National strategic targets should not be confused with tactical level targets. The tactical level is meant to serve the needs of identified targets, which is the key to distinguishing between national strategic targets and tactical level goals. When the strategic, tactical and operational levels harmonize with each other, the transition process takes place in a reflexive way.

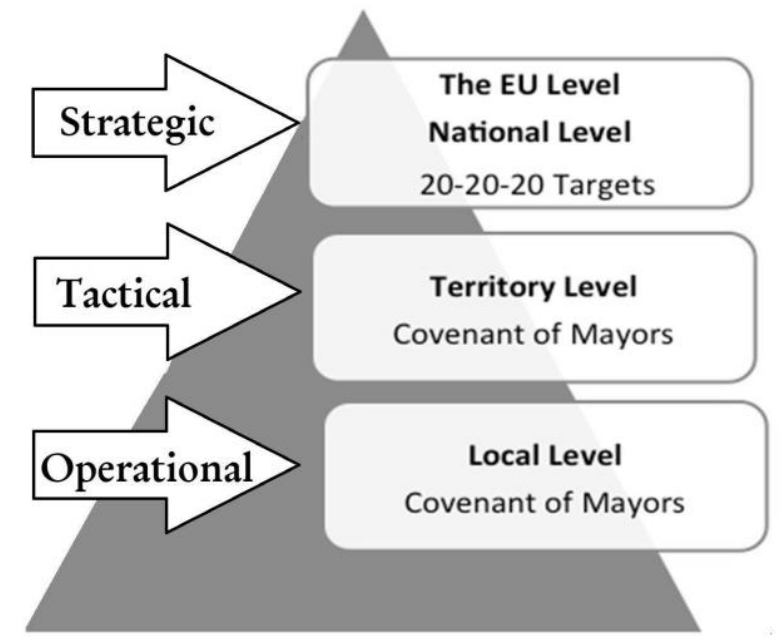

Figure 7. Strategic, tactical and operational levels of the EU 20-20-20

Source: based on Arababadi et al. (2017)

"Transition management" supposes that these activities should offer specific attributes in terms of what actors are partaking in the process, what processes they are interlinked with, and what type of product or service they generate, which can make the design of specific system tools and process strategies possible. As an example, we could mention changing partakers (designating a target group), defining the challenge in the specific transition process, the type of processes required for success, or the use of process regulation tools (Wittmayeret al., 2017). 
However, several authors note that different economic and social development are generating processes at different speeds during the transition process. Due to conscious but too fast or slow developments may lead to undesirable and non-sustainable transformations. (Roaf et al., 2014; Campos\&Coricelli, 2002). In addition, it is of the utmost importance for comparability that a similarly macroeconomic environment and consumption culture characterize the systems studied (Žídek, 2014).

\section{METHODOLOGY}

To test and determine the validity of our theoretic model, and to fine-tune interpretation, we used quantitative techniques. The gathering of quantitative data occurred during two projects, differing both geographically and time-wise. The data gathering in Hungary was done by Szent Istvan University's Marketing Institute during an omnibus research with 1039 participants, 411 of whom met the 'fifty plus' criterion of our research; therefore, our analysis included answers from this segment (Fogarassy et al., 2014; Lehota, 2013). The relevant question groups of the Hungarian research were used again, with identical form and conditions during the Swiss quantitative research, with a sample of 202 participants. The complete process of the research can be seen in Table 1.

Table 1

Summarization of research methods

\begin{tabular}{|c|c|c|c|c|}
\hline $\begin{array}{l}\text { Research } \\
\text { method }\end{array}$ & $\begin{array}{c}\text { Research } \\
\text { date }\end{array}$ & $\begin{array}{l}\text { Research } \\
\text { location }\end{array}$ & $\begin{array}{l}\text { Research } \\
\text { focus }\end{array}$ & Sample \\
\hline Questionnaire & 2013 & Hungary & $\begin{array}{l}\text { - Values; } \\
\text { - Respecting } \\
\text { traditions; } \\
\text { - } \quad \text { Worries about } \\
\text { sustainability; } \\
\text { - } \quad \text { Foodstuff } \\
\text { expectations; } \\
\text { - Consumer habits, } \\
\text { demo-graphic identification }\end{array}$ & $\begin{array}{l}\text { Sample is nationally } \\
\text { representative. } \\
\text { Full sample: } 1039 \\
50+\text { bracket: } 411\end{array}$ \\
\hline Questionnaire & 2014 & Switzerland & $\begin{array}{l}\text { - } \\
\text { - } \\
\text { salues; } \\
\text { sustainability; } \\
\text { - } \quad \text { Foodstuff } \\
\text { expectations; } \\
\text { - } \\
\text { demo-graphic identification }\end{array}$ & $\begin{array}{l}\text { Full sample: } 202 \text { head } \\
50+\text { bracket: } 202 \text { head }\end{array}$ \\
\hline
\end{tabular}

Source: based on Fogarassy at al. (2014)

The importance of the question is supplemented by the fact that worries, as emotional tools, can subconsciously provide both negative motivations, and on a cognitive level, influence our decisions at the same time. The research was basically oriented to explore the worries of senior Hungarian consumers. For the objective evaluation, we analysed and used the main points of the Swiss target group's worries, and then explored whether the Hungarian fifty plus population's formula of self-conscious consumer habits have any relation to their worries regarding their sustainable environment and health. In the case of the Hungarians questioned, the perspective of the world which can be seen was somewhat introverted. 


\section{RESULTS AND DISCUSSION}

Our participants looked at the problems currently occurring around the globe from a subjective point of view, as they could only relate to their personal problems when decoding their meaning. They could not look at the bigger picture. Global sustainability could be pictured through the results obtained from the questionnaire, projected onto the target group's problems. We structured the questionnaire to form the question groups as negatively as possible; furthermore, in such a way that they do not relate to the respondents answering them (Figure 8). This obviously resulted in the fact that most of our participants tended to the higher end of the scale, thereby dispelling their cognitive dissonance when answering the questions (Lehota et al., 2013). The conclusion was that our topics, or quasi objects of research were placed within narrow margins $(4.1-4.6 / 5)$, which means that in the inherent information content, both the relative position and the comparison made with the Swiss sample was higher than the absolute numbers. The qualitative research shows that having their own experiences of the topic made participants more worried. As a result, topics like water (Contamination of potable water: 4. 6/5; Depletion of water reserves: 4. 6/5), air pollution (Contamination of air: 4. 5/5), and foodstuff safety (Hazards of new food processing technologies: 4.5/5; Toxic heavy metals: 4. 5/5; Pesticide remains in food: 4. 5/5; Genetic manipulation/GMOs: 4.5/5) constitute the most notable topics of concern. This also contributed to the fact that question groups dealing with contamination scored 4.5/5. The over-fifty participants placed the problems with a more substantial indirect impact, such as over-population, the extinction of species, malnutrition, and the accumulation of waste related to foodstuffs, lower on the list of worrying factors.

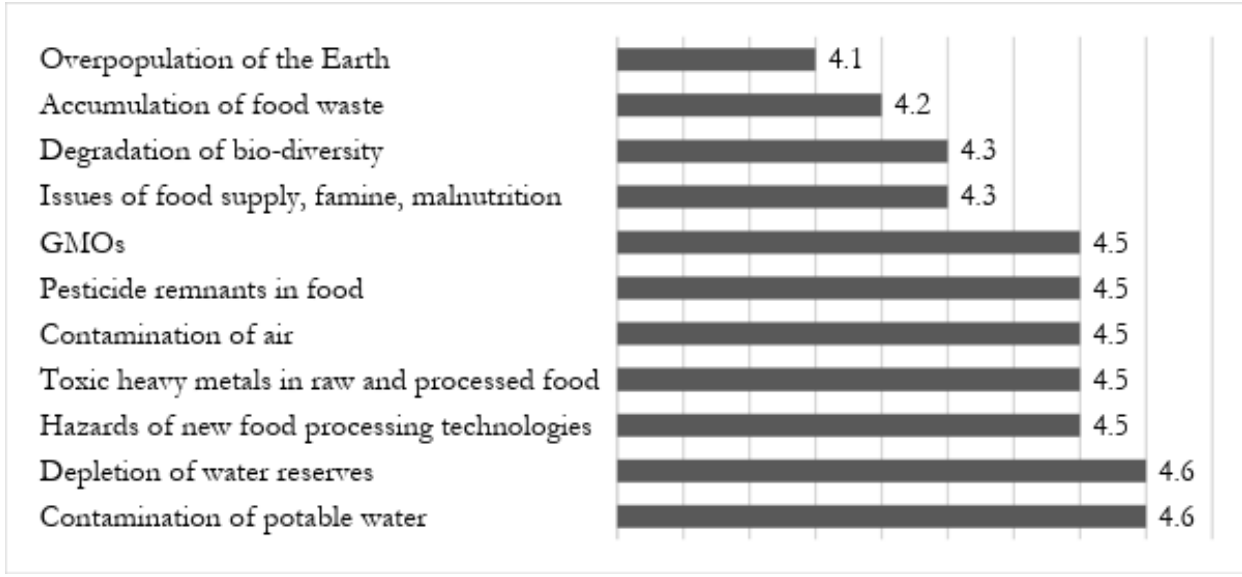

Figure 8. Fears of the Hungarian Target Population (averages)

Source: authors' own calculation

The most notable connection we can find is between the personal experiences related to the topic in question, and the impact it has on the participant's opinion. If we look at the Hungarian and the Swiss samples, another connection of note also appears: the former are more interested in more detached worries, whereas the latter consider more down-to-earth ones more important. This may be related to the idea that some people maintain that Swiss people's thinking is more advanced. Hungarians also think of Global Warming $(+0.4)$, the Depletion of energy resources $(+0.5)$, and Animal to human diseases $(+0.3)$ as more important than the Swiss. As we can see in Figure 9, Hungarians and Swiss mainly agree on the level of importance of combined contamination values and worries related to food reserves. Contrary to this, local environment attributes seem to have a distinctly different importance for the two groups. Swiss participants consider these more apparent (forest areas are thinning, water reserves become depleted, hazardous waste 
is accumulated, the soil is becoming more and more contaminated). They see this as a consequence of the degrading of the local environment. We feel the need to stress the fact that these measurements were conducted in 2014, as the Hungarian target group's answers (placing more importance on global warming, the shortage of energy resources, or species extinction) are from 2013.

\begin{tabular}{|c|c|c|}
\hline Soil contamination & -0.6 & \\
\hline Accumulation of hazardous waste & -0.6 & \\
\hline Depletion of water reserves & -0.4 & \\
\hline Degradation of forests & -0.2 & \\
\hline Animal-to-human diseases & & \\
\hline Global warming and climate degragation & & 0.4 \\
\hline Depletion of energy resources & & 0.5 \\
\hline
\end{tabular}

Figure 9. Fears of the Hungarian target population - comparison with the elderly Swiss target population (averages)

Source: authors' own calculation

The results shown in Figure 9 represent well that our hypothesis is justified in the research. To accelerate the same goals (increase sustainable consumption), we need to use different tools / strategies for countries with different degrees of development. In systems with different levels of development, therefore, the speed of changes affecting consumption can be significantly different. It is also clear from the partial results that the use of inadequate strategies can lead to a distorted development path.

\section{CONCLUSION}

According to our findings from the quantitative section, we can state that the Hungarian fifty plus generation is most notably price-sensitive; in other words, if we change prices, their habits as consumers can be rearranged for a short, or possibly mid-length period. Which means tactical transition management is capable of maintaining their sustainable consumer habits. This is also the most widely used method of changing the structure of consumer habits - by, for example, central price regulations, the service system of the government, and expenditure cuts - in Hungary. However, we can see that if these tools are put to use, elderly Hungarians sink deeper into habits which are the exact opposite of sustainable and low-carbon lifestyle choices. If the cost of energy is reduced, consumption increases. Similarly, if expenses are cut, wasting water becomes a problem. Therefore, we can say our research came up with similar results to the OECD's 2008 study. Tactical management tools can usher us towards developing a transition to a sustainable economy, also resulting in "transition thinking". This happens, of course, only as long as they are aided by forming central institutions (sources of education and marketing activities), regulatory systems (which regulate prices, and give a push to programs), and physical infrastructure (pilot systems). In Hungary, the implementation of tactical tools such as the introduction of the "chip tax" or "public health product tax", was a good example of this, and meant reducing the Hungarian population's consumption of nonhealthy foods (soft drinks with high sugar content, energy drinks, snacks, salt products, flavoured beers etc.). Using the tool, however, you have to be careful about whether you can reduce your consumption or even increase prices or inflation (Járomi et al., 2016). 
This entire method is useless for the Swiss however, given that since their habits are not formed on the basis of price, they are not influenced as strongly by the appearance of their products or services, which also means marketing ploys and tools are less effective in influencing them. Instead, they consume on the basis of a distinct, short-term, and day-by-day modus operandi that has its roots in how they perceive their close environment at the time of the purchase. Our quantitative research strongly suggests elderly Swiss consumers' list price as a barely important factor, which makes using price control as a method of changing their habits redundant, and mostly useless. Naturally, this means that the means to change their thinking is fundamentally different from that used for Hungarians. As we have already discussed, the Swiss take note of global problems less when compared to Hungarians - climate change and energy resources becoming more scarce mean less to the Swiss, which means that rather than Reflexive transition management, the key to making Swiss consumers' habits lean towards sustainability management may be Operative transition management. Swiss over-50s (at least those in the sample) generally strive for autonomy as much as possible. This causes the actors in their economy to discard simplified changes to their systems, and turn towards the option of debating either a restructuring (if the results are satisfactory), or a reconstruction (if necessary). The study found that the sustainable consumption patterns of Swiss consumers over 50 are not affected by price changes or global catastrophes, but by the state of the local environment. Consumers decided on the positive or negative information from the local environment. Information related to negative environmental changes in the local environment can be easily detected in the purchasing habits of Swiss consumers over 50. If they receive negative environmental information about their living area, environmentally conscious shopping will increase.

\section{REFERENCES}

Arababadi, R., Moslehi, S., Mounir, El Asmar, Haavaldsen, T. \& Parrish, K. (2017). Energy policy assessment at strategic, tactical, and operational levels: Case studies of EU 20-20-20 and U.S. Executive Order 13514, Energy Policy, 109, 530-538. https://doi.org/10.1016/j.enpol.2017.07.042.

Brooks Harvey. (1995). What We Know and Do Not Know about Technology Transfer: Linking Knowledge to Action. in: Marshalling Technology for Development, Proceeding of a Symposium. NAP W ashington DC, 92.

Campos, N., \& Coricelli, F. (2002). Growth in Transition: What We Know, What We Don't, and What We Should. Journal of Economic Literature, 40(3), 793-780. Retrieved from http://www.jstor.org/stable/3217110

Fogarassy, C., Szarka, K. \& Lehota, J. (2014). The "transition thinking” and 50plus generation thoughts of sustainability in different countries (case study in Hungary and Switzerland). International Journal of Advanced Research in Management and Social Sciences, 3(11), 33-48.

Fogarassy, C. \& Neubauer, E. (2016). Evaluation of the regional water usage in Hungary with water allowance coefficient (WAC). Applied Ecology and Environmental Research, 14(1), 161-173. https://doi.org/10.15666/aeer/1401 161173

Horvath, B. \& Magda, R. (2017). Possible bottlenecks in the strategic management of environmentally engaged companies - transition to the world of circular businesses. Paper presented at the SMSIS 2017 - Proceedings of the 12th International Conference on Strategic Management and its Support by Information Systems, 11-20.

Hungarian Central Statistical Office (HCSO) (2018). Hungary Food Inflation Chart. Retrieved from https://tradingeconomics.com/hungary/food-inflation

Hungarian Academy of Science (HAS). (2017). Water in Hungary Status overview for the National Water Programme of the Hungarian Academy of Sciences, Budapest, 17. Retrieved from http://mta.hu/data/dokumentumok/Viztudomanyi\%20Program/Water in Hungary 201707 20.pdf

Illés, B. Cs., Hurta, H. \& Dunay, A. (2015). Efficiency and Profitability Along the Lifecycle Stages of Small Enterprises. International Journal of Management and Enterprise Development, $14(1), \quad 59$. http://dx.doi.org/10.1504/IJMED.2015.069311

Járomi, É., Szűcs, E. \& Vitrai, J. (2016). Planning behavior change interventions tailored to healthstyles, Egészségfejlesztés, LVII., 2., 34-42. 
Kemp, R., Loorbach, D. \& Rotmans, J. (2007). Transition management as a model for managing processes of coevolution towards sustainable development. International Journal of Sustainable Development \& World Ecology, 14(1), 78-91, DOI: 10.1080/13504500709469709

Kot, S. (2018) Sustainable supply chain management in small and medium enterprises. Sustainability, 10(4), art. no. 1143, DOI: $10.3390 /$ su10041143

Lefebvre, M., Maria, E., Sergio, G. P., Maria, L. P., Annette, P. \& Ingo, Z. (2014). Agricultural landscapes as multiscale public good and the role of the Common Agricultural Policy, Journal of Environmental Planning and Management, 58(12), 2088-2112. http://dx.doi.org/10.1080/09640568.2014.891975

Lehota, J., Horvath, A. \& Racz, G. (2013). The effect of sustainability on the information search behaviour of Hungarian consumers through the practice of food purchasing. Acta Alimentaria, 43(3), 437-443. http://dx.doi.org/10.1556/AAlim.43.2014.3.10

Loorbach, D. \& Rotmans, J. (2009). The practice of transition management: Examples and lessons from four distinct cases. Futures, 42(3), 237-246. http://dx.doi.org/10.1016/i.futures.2009.11.009

Loorbach, D. (2010). Transition Management for Sustainable Development: a Prescriptive, Complexity-Based Governance Framework. Governance, 23(1), 161-183. http://dx.doi.org/10.1111/j.1468-0491.2009.01471.x

Máté, D., Oláh, J., Lakner, Z., Popp, J. (2017) Food chemistry patents influence on productivity: A case study of a sectoral approach in various OECD countries. Polish Journal of Management Studies, 16 (2), 160-170. DOI: 10.17512/pjms.2017.16.2.14

OECD (2008). Promoting Sustainable Consumption. GOOD PRACTICES IN OECD COUNTRIES, 2008, 45 http://www.oecd.org/greengrowth/40317373.pdf

Roaf, J., Atoyan, R., Bikas, J., \& Krogulski, K. (2014). 25 Years of Transition Post-Communist Europe and the IMF Regional Economic Issues Special Report, International Monetary Fund, Publication Services, Washington, 5-7. http://www.imf.org/external/region/bal/rr/2014/25 years of transition.pdf

Roorda, C., Frantzeskaki, N-Loorbach, D., Steenbergen, F. \& Wittmayer, J. (2012). Transition management in Urban Context. DRIFT Report, Rotterdam, 32-40.

Ryan, C. (2013). Eco-Acupuncture: designing and facilitating pathways for urban transformation for a resilient lowcarbon future. Journal of Cleaner Production, 50, 189-199. http://dx.doi.org/10.1016/j.jclepro.2012.11.029

Springer, U. (2006). Linking domestic emissions trading schemes to the EU ETS (ECOPlan). Retrieved from http://player.slideplayer.com/15/4508695/data/images/img1.jpg

Sterrenberg, L., Andringa, J., Loorbach, D., Raven, R. \& Wieczorek, A. (2013). Low-carbon transition through system innovation: Theoretical notions and applications. Pioneers into Practice mentoring program 2013. http://repository.tue.nl/fcf3b9ec-ba7d-4982-bc43-70b3a93721cf

Sylvia, L. \& Doris, F. (2013). Strong sustainable consumption governance - precondition for a de-growth path? Journal of Cleaner Production, 38, 36-43. http://dx.doi.org/10.1016/j.jclepro.2011.08.008

Wittmayer, J.M., van Steenbergen, F., Rok, A. \& Roorda, C. (2016). Governing sustainability: a dialogue between Local Agenda 21 and transition management. Local Environment, 21 (8), 939-955, doi: 10.1080/13549839.2015.1050658

Wittmayer, J. M., Avelino, F., van Steenbergen, F., \& Loorbach, D. (2017). Actor roles in transition: Insights from sociological perspectives. Environmental Innovation and Societal Transitions, 24, 45-56. https://doi.org/10.1016/j.eist.2016.10.003.

World Factbook CIA. (2018). Population pyramid in Switzerland and Hungary. https://www.cia.gov/library/publications/the-world-factbook/geos/hu.html

Žídek, L. (2014). Evaluation of Economic Transformation in Hungary. Review of Economic Perspectives, 14(1), 55-88. https://doi.org/10.2478/revecp-2014-0004 